\title{
Author Correction: Highly recurrent CBS epimutations in gastric cancer CpG island methylator phenotypes and inflammation
}

\author{
Nisha Padmanabhan ${ }^{1}$, Huang Kie Kyon ${ }^{1 \dagger}$, Arnoud Boot ${ }^{2 \dagger}$, Kevin Lim', Supriya Srivastava ${ }^{3}$, Shuwen Chen ${ }^{4}$, \\ Zhiyuan Wu ${ }^{5}$, Hyung-Ok Lee ${ }^{6}$, Vineeth T. Mukundan7 , Charlene Chan ${ }^{7}$, Yarn Kit Chan ${ }^{1}$, Ong Xuewen ${ }^{1}$, Jason J. Pitt ${ }^{7}$, \\ Zul Fazreen Adam Isa', Manjie Xing ${ }^{1}$, Ming Hui Lee ${ }^{1}$, Angie Lay Keng Tan', Shamaine Ho Wei Ting ${ }^{1}$, \\ Micah A. Luftig ${ }^{8}$, Dennis Kappei ${ }^{7,9}$, Warren D. Kruger ${ }^{6}$, Jinsong Bian ${ }^{5,10}$, Ying Swan Ho ${ }^{4}$, Ming Teh ${ }^{11}$, \\ Steve George Rozen ${ }^{2}$ and Patrick Tan ${ }^{1,7,12,13,14,15^{*}}$
}

The original article can be found online at https://doi.org/10.1186/ s13059-021-02375-2.

* Correspondence: gmstanp@ dukenus.edu.sg

${ }^{\dagger}$ Huang Kie Kyon and Arnoud Boot contributed equally to this work. ${ }^{1}$ Programme in Cancer and Stem Cell Biology, Duke-NUS Medical School, 8, College road, Singapore 169857, Singapore

${ }^{7}$ Cancer Science Institute of Singapore, National University of Singapore, Singapore 117599, Singapore

Full list of author information is available at the end of the article

\section{Correction to: Genome Biol 22, 167 (2021) https://doi.org/10.1186/s13059-021-02375-2}

Following publication of the original article [1], the authors identified an error in the author name of Hyung-Ok Lee.

The incorrect author name is: Hyung-O K Lee

The correct author name is: Hyung-Ok Lee

The author group has been updated above and the original article [1] has been corrected.

\begin{abstract}
Author details
'Programme in Cancer and Stem Cell Biology, Duke-NUS Medical School, 8, College road, Singapore 169857, Singapore. ${ }^{2}$ Centre for Computational Biology, Duke-NUS Medical School, Singapore 169857, Singapore. ${ }^{3}$ Department of Medicine, Yong Loo Lin School of Medicine, National University of Singapore, Singapore 119228, Singapore. ${ }^{4}$ Bioprocessing Technology Institute, A*STAR, 20 Biopolis Way, \#06-01 Centros, Singapore 138668, Singapore. ${ }^{5}$ Department of Pharmacology, Yong Loo Lin School of Medicine, National University of Singapore, Singapore 117600, Singapore. ${ }^{6}$ Cancer Biology Program, Fox Chase Cancer Center, Philadelphia, PA, USA. ${ }^{7}$ Cancer Science Institute of Singapore, National University of Singapore, Singapore 117599, Singapore. ${ }^{8}$ Department of Molecular Genetics and Microbiology, Duke Centre for Virology, Duke University School of Medicine, Durham, NC, USA. ${ }^{9}$ Department of Biochemistry, Yong Loo Lin School of Medicine, National University of Singapore, Singapore 117596, Singapore. ${ }^{10}$ National University of Singapore (Suzhou) Research Institute, Suzhou 215123, China. ${ }^{11}$ Department of Pathology, National University of Singapore, Singapore 119228, Singapore. ${ }^{12}$ Genome Institute of Singapore, Singapore 138672, Singapore. ${ }^{13}$ SingHealth/Duke-NUS Institute of Precision Medicine, National Heart Centre Singapore, Singapore 169856, Singapore. ${ }^{14}$ Singapore Gastric Cancer Consortium, Singapore 119074, Singapore. ${ }^{15}$ Department of Physiology, National University of Singapore, Singapore 117593, Singapore.
\end{abstract}

Published online: 17 June 2021

\section{Reference}

1. Padmanabhan N, Kyon HK, Boot A, et al. Highly recurrent CBS epimutations in gastric cancer CpG island methylator phenotypes and inflammation. Genome Biol. 2021;22:167 https://doi.org/10.1186/s13059-021-02375-2.

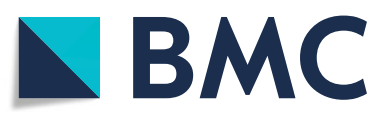

( The Author(s). 2021 Open Access This article is licensed under a Creative Commons Attribution 4.0 International License, which permits use, sharing, adaptation, distribution and reproduction in any medium or format, as long as you give appropriate credit to the original author(s) and the source, provide a link to the Creative Commons licence, and indicate if changes were made. The images or other third party material in this article are included in the article's Creative Commons licence, unless indicated otherwise in a credit line to the material. If material is not included in the article's Creative Commons licence and your intended use is not permitted by statutory regulation or exceeds the permitted use, you will need to obtain permission directly from the copyright holder. To view a copy of this licence, visit http://creativecommons.org/licenses/by/4.0/. The Creative Commons Public Domain Dedication waiver (http://creativecommons.org/publicdomain/zero/1.0/) applies to the data made available in this article, unless otherwise stated in a credit line to the data. 